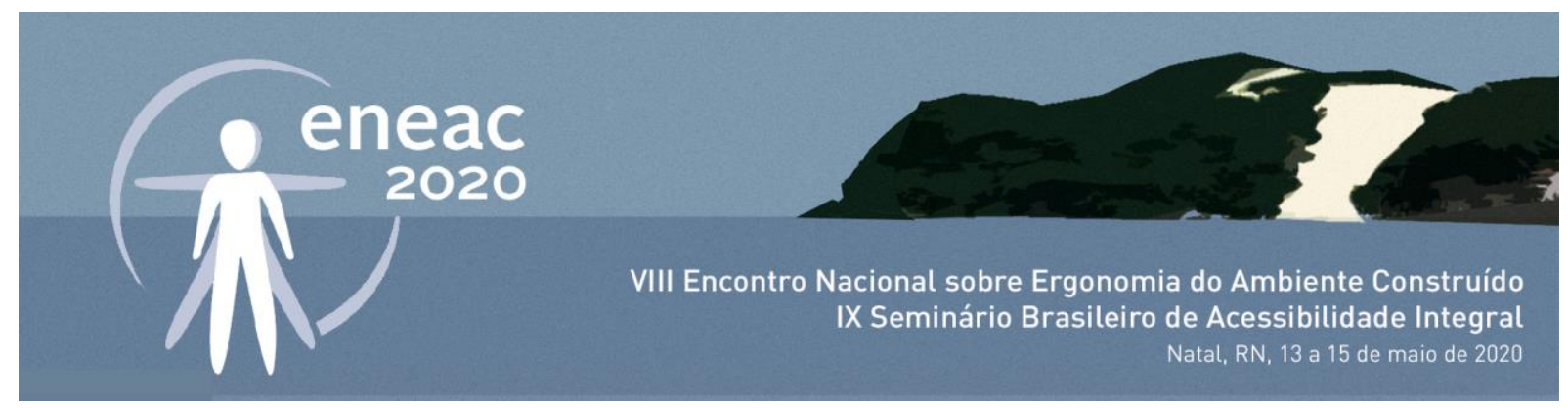

\title{
Acessibilidade no complexo da Basílica de São Francisco em Canindé - CE
}

\section{Accessibility in the San Francisco Basilica complex at Canindé - CE}

\author{
MANUELA DE CASTRO MENDONÇA LIMA \\ Pós-Graduanda, Universidade Federal do Ceará, manucml@gmail.com \\ JOSÉ RÓGERES MAGALHÃES COSTA \\ Especialista, Tribunal de Justiça do Ceará, rogerescosta@hotmail.com \\ FERNANDO HENRIQUE AZEVEDO SANTOS \\ Graduado, Universidade Federal do Ceará, fernandohenrique_as@hotmail.com \\ STEPHANIE CIQUEIRA SILVA \\ Graduada, Universidade Federal do Ceará, stph.arquitetura@gmail.com
}

\section{RESUMO}

Anualmente a cidade de Canindé, que fica no interior do Ceará, recebe milhares de visitantes vindos de diversos lugares do Brasil, durante a grande Festa de São Francisco das Chagas, que acontece entre os meses de setembro e outubro. Os visitantes, que são mais conhecidos como Romeiros, viajam para a cidade para expressar sua fé, pagar suas promessas, agradecer e fazer pedidos ao santo que faz parte da identidade do local. O grande evento, que se estende por dias, acaba se tornando uma grande manifestação cultural, religiosa e turística, trazendo muitos benefícios a cidade. Mas, a estrutura urbana do local pode ser considerada inacessível, pois, sendo uma parcela expressiva do público visitante composta por pessoas idosas e com deficiência, a inexistência de rampas de acesso e sinalizações inclusivas ressaltam-se claramente. Este artigo tem como objetivo analisar o trecho religioso mais visitado pelos romeiros através da técnica do "walkthrough evaluation" e observar as problemáticas existentes.

PALAVRAS-CHAVE: Canindé, fluxos, acessibilidade

\section{ABSTRACT}

Every year, the city of Canindé, which is located in the countryside of Ceará, receives thousands of visitors from various places in Brazil, during the large festival of São Francisco das Chagas, which happens between September and October. Visitors, who are better known as 'Romeiros', travel to this city to express their faith, pay their promises, thank and ask for blessings to the saint who is part of the local identity. The big event, that last for days, ends up becoming a great cultural, religious and tourist event, bringing many benefits to the city. However, the urban structure of the place can be consideredinaccessible, since being an expressive portion of the visiting public composed of elderly and disable people, the lack of access ramps and inclusive signs is clearly highlighted. This article aims to analyze the religious section most visited by pilgrims through the technique of "walkthrough evaluation"and the existing problems. 


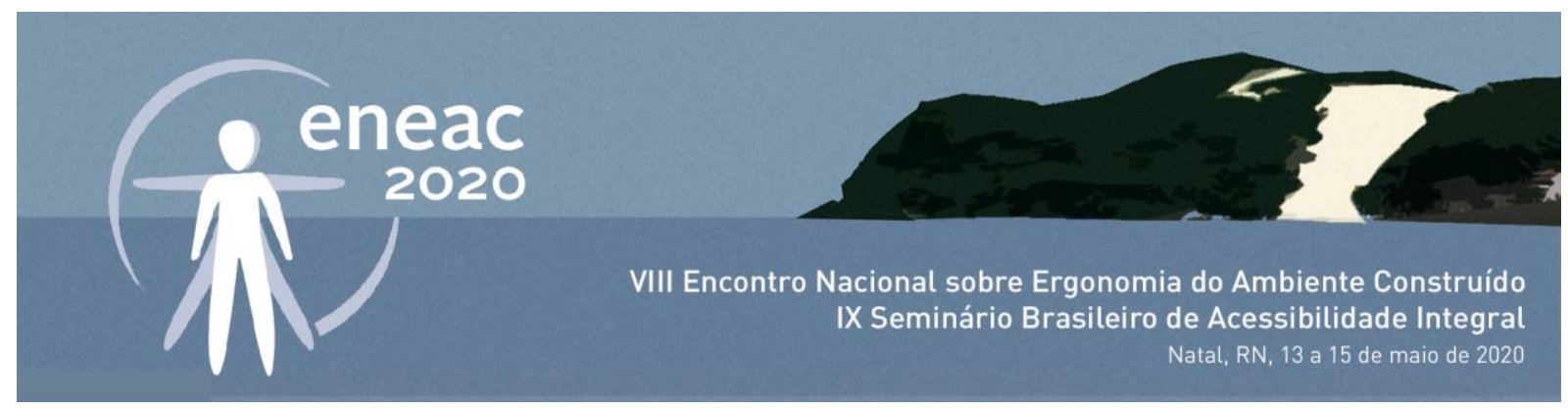

KEYWORDS: Canindé, flows, accessibility

\section{INTRODUÇÃO}

De acordo com a definição do dicionário Aurélio, a romaria é uma peregrinação de caráter religioso e o peregrinar é o ato de viajar ou andar por terras distantes. Acredita-se que as primeiras romarias no Brasil datam do ano de 1750, sendo essas trazidas pelos portugueses. A ação tinha como principal objetivo o agradecimento dos devotos às graças alcançadas por uma promessa.

Em romarias típicas do Nordeste brasileiro, o ato de agradecer faz com que as pessoas se desloquem para os lugares simbolicamente sagrados onde elas possam depositar suas oferendas na forma de objetos que se refiram à sua promessa - os ex-votos. A Casa dos Milagres é um dos locais onde as pessoas de fé costumam deixar os seus ex-votos; pois, agradecer a uma dádiva alcançada é uma honra e, ao mesmo tempo, um dever aos romeiros. Assim, nada os impedem de ir até estes lugares sagrados como demonstração de fé e devoção.

No Ceará, as cidades de Juazeiro do Norte e Canindé se destacam por serem lugares de devoção à Padre Cícero Romão Batista e São Francisco das Chagas, respectivamente. A fé acreditada a estas duas figuras da religião católica faz com que estas cidades sejam visitadas por peregrinos durante o ano todo, principalmente em períodos de festejos ou romarias.

Canindé, situada no sertão central do Ceará, é o segundo maior polo de devoção à São Francisco no mundo; ficando atrás apenas da cidade natal do santo - Assis na Itália. Durante o período de grande romaria, entre os meses de setembro e fevereiro, a cidade chega a receber 300 mil pessoas. Toda a parte urbana da cidade fica repleta de romeiros peregrinando em cada ponto religioso da cidade. Mas, o lugar que mais se destaca e que é o mais visitado no município é o complexo da Basílica. Até o ano de 2008, a Basílica Menor de São Francisco das Chagas era a única de todo o estado do Ceará e, para os nativos, simboliza o lugar de nascimento da cidade. Assim, as primeiras edificações de todo o complexo religioso em devoção a São Francisco surgiram nas adjacências da Basílica.

Atualmente, milhares de pessoas de todas as idades, classes sociais e lugares do Brasil se deslocam para Canindé anualmente, mas, mesmo com toda esta forte peregrinação, a cidade continua com problemas físicos que comprometem o acolhimento dos seus romeiros e/ou devotos franciscanos. A ausência de equipamentos para abrigar os visitantes é algo que há muito tempo se discute na cidade além da questão da falta de acessibilidade, um fato marcante no lugar. Este problema dificulta a circulação dos visitantes que possuem alguma deficiência ou mobilidade reduzida. Ressalta-se que, uma parcela dos romeiros de Canindé é formada por idosos; ou seja, são pessoas com mobilidade comprometida e com dificuldades de subir escadas, fazer caminhadas de longas distâncias e permanecer muito tempo de pé.

Assim, o presente artigo busca observar como esta falta de acessibilidade no complexo da Basílica é prejudicial aos visitantes e nativos. Os diversos obstáculos nos percursos externos entre as principais edificações vão desde barreiras físicas arquitetônicas até barreiras atitudinais provocadas pelas pessoas que ali frequentam ou trabalham. 


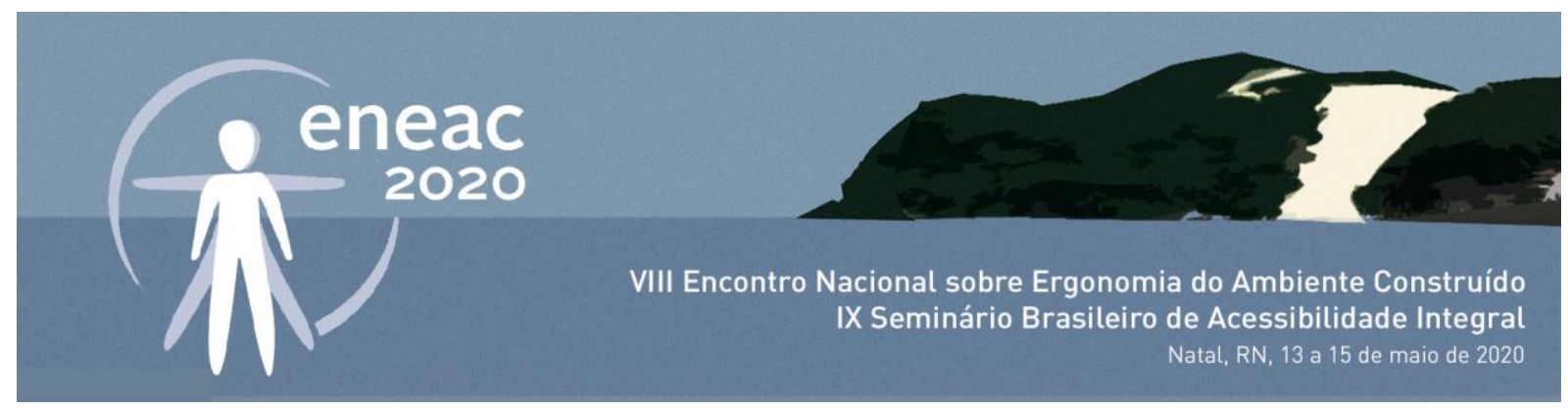

A metodologia utilizada para este trabalho desenvolveu-se através de levantamentos em campo e observações diretas; além de percorrer os caminhos realizados pelos romeiros para acessar as principais edificações do complexo. O método, criado por Preiser et al. (1988) chamado de "walkthrough evaluation", tem como objetivo identificar pontos relevantes da acessibilidade espacial através de um percurso feito no espaço analisado; pois, a articulação dos usuários está diretamente relacionada aos aspectos físicos do ambiente por eles utilizados.

A pesquisa também consiste em registros fotográficos, desenhos, anotações, além de uma pesquisa bibliográfica sobre os temas de caminhabilidade e de acessibilidade; incluindo regulações que se referem ao tema (Decreto 5.296/2004 e normas NBR 9050/2015 e NBR 16537/2016). Com a utilização de dados técnicos encontrados nas regulações, poder-se-á discutir as problemáticas encontradas e os seus respectivos reflexos nas atitudes dos usuários do espaço analisado.

\section{A QUESTÃO DA ACESSIBILIDADE}

De acordo com a Nota técnica 01/2018 do censo de 2010 do Instituto Brasileiro de Geografia e Estatística (IBGE), 6,7\% da população brasileira afirmava ter algum tipo de deficiência. Este valor substituiu o de $23,9 \%$ mencionado anteriormente em outra modalidade de pesquisa do próprio IBGE. O motivo dessa diminuição considerável se deu após uma nova postura nas pesquisas sociais na qual o instituto passou a identificar eventuais lacunas deixadas nas metodologias anteriores. Na questão da deficiência, o censo passou a contar apenas as pessoas que assinalavam determinados pontos; além de levar em consideração as respostas dos entrevistados e as suas avaliações em relação às ações de enxergar, ouvir, caminhar ou subir escadas. A partir das respostas, os resultados foram dimensionados em uma escala de dificuldade que começa com "nenhuma dificuldade" e segue com "alguma dificuldade", "muita dificuldade" e "não consegue de modo algum". De acordo com o jornal Estadão (2018), esta nova modalidade de avaliação foi baseada no documento chamado Panorama Nacional e Internacional da Produção de Indicadores Sociais que utiliza recomendações internacionais da Organização das Nações Unidas (ONU) e da Organização Mundial da Saúde (OMS).

Observando os dados de pessoas com deficiência no Brasil, a cidade de Canindé, com uma população de 78 mil habitantes (IBGE, 2018), apresentava no cadastro do Sistema de Informação da Atenção Básica (SIAB) do Ministério da Saúde 784,99 casos de deficiência física a cada 100 mil pessoas (SIAB, 2013). Ressalta-se que, no cadastro do SIAB, até julho de 2013 , apenas $57 \%$ da população brasileira era cadastra no sistema. Ou seja, além de faltar a outra parcela de $43 \%$ da população, o dado já apresenta uma desatualização expressiva de sete anos.

Cabe ressaltar que este dado se refere apenas à Canindé e, como já fora mencionado, a cidade recebe visitantes do Brasil todo; ou seja, o dado sobre o número de deficientes na localidade é parcial se levarmos em consideração a quantidade de pessoas que vão ao município em romaria ou em visitação turística. 


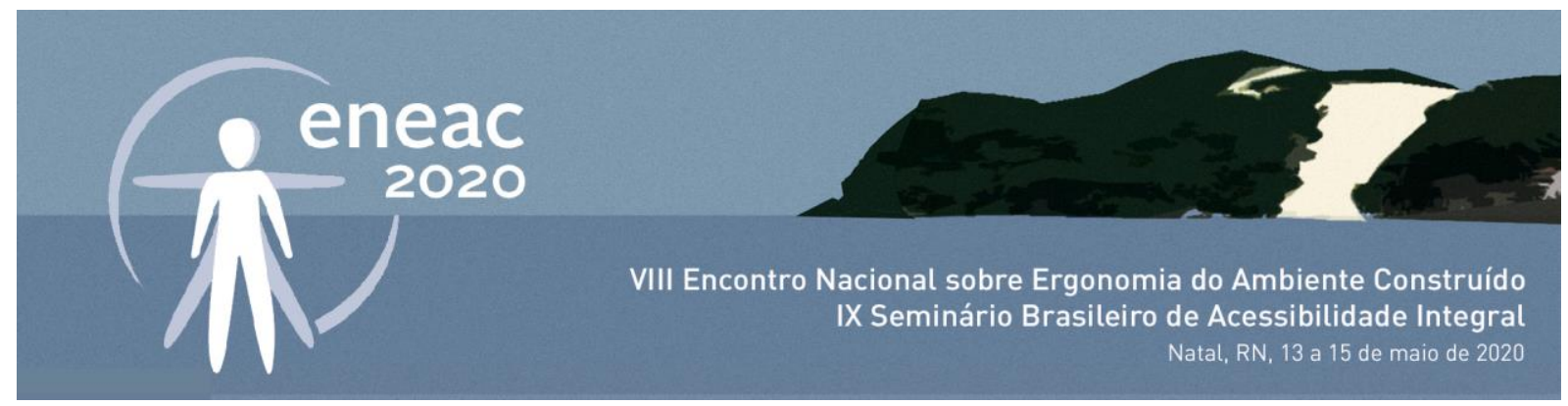

Gráfico 1: Incidência de casos de deficiência física em Canindé

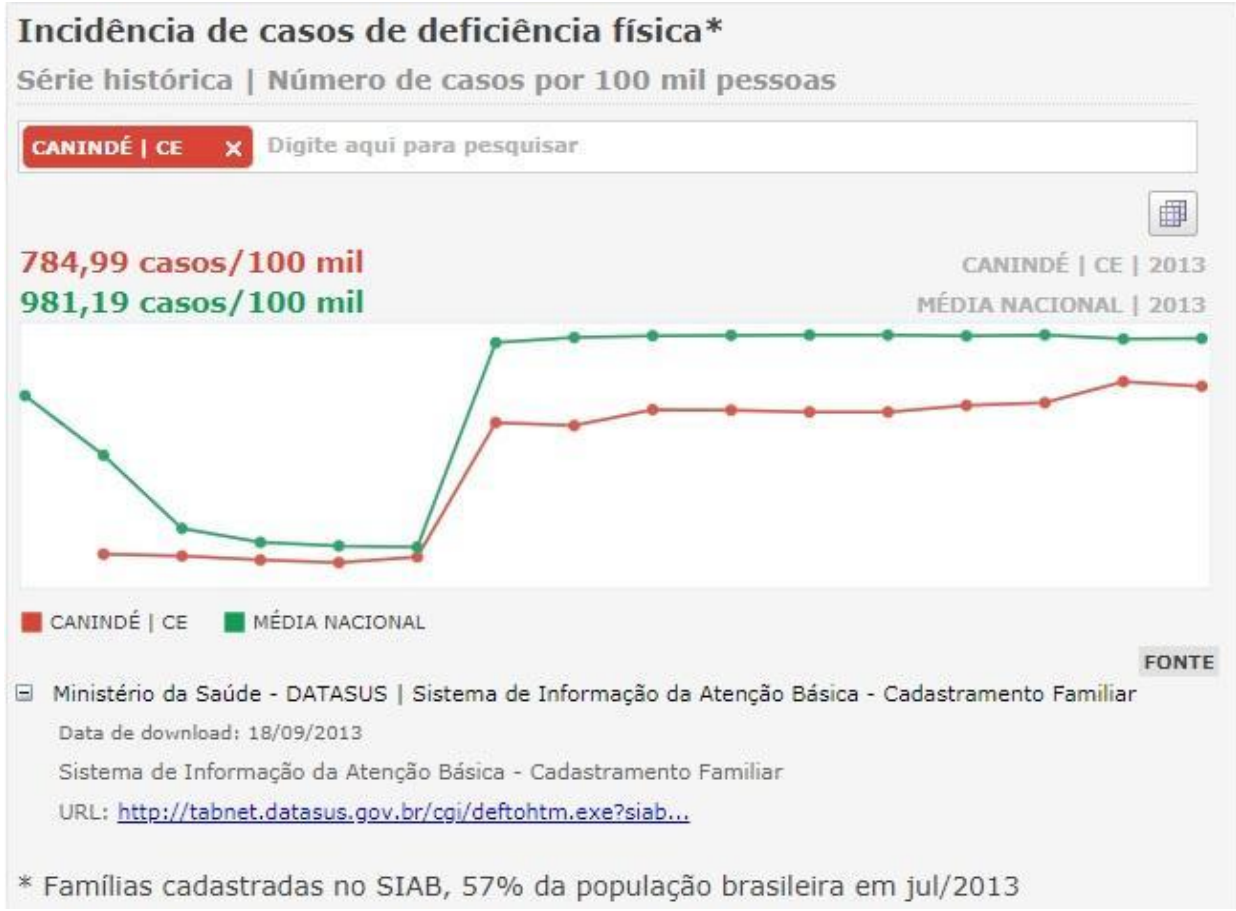

Fonte: Jornal Estadão (2018).

Tentar frequentar um espaço que não permite um percurso independente e livre de barreiras, é sinal de que o lugar é segregador. Por mais que a devoção diminua a dor e o sacrifício da promessa, o espaço não pode tirar partido dessa entrega corporal feita pelos seus devotos. Apesar da questão religiosa, Canindé também pode ser considerada como uma cidade turística para as pessoas que vão visitar e entender a romaria franciscana.

Outro ponto importante é que o espaço tem que ser caminhável, ou seja, permitir que os frequentadores percorram por todos os ambientes de maneira prazerosa e com o mínimo de esforço. Para esta caminhada agradável, Gehl (2013) diz que o espaço tem que ser livre de obstáculos que possam causar desvios desnecessários. Além disso, ressalta-se que os percursos existentes entre as edificações do complexo da Basílica fazem parte do desenho da cidade; permitindo a circulação das pessoas que ali transitam independente das celebrações religiosas.

As vias que circundam o perímetro do complexo da Basílica também se destacam, pois, possuem calçadas estreitas, muitas vezes com grandes desníveis e degraus; fazendo com que as pessoas optem por caminhar no leito carroçável revestido por pedras de corte bruto e pontiagudas, criando um plano acidentado e tornando a caminhabilidade desconfortável e favorecendo acidentes.

Mas, mesmo considerando a eliminação das barreiras ou obstáculos algo fundamental para se obter um espaço inclusivo, para Duarte e Cohen (2010), isso não é tudo. O espaço inclusivo tem que gerar afeto ao usuário, haver identificação e uma relação de conhecimento. Canindé gera esta identificação para a grande maioria dos seus frequentadores, pois, apesar das condições não ideais encontradas pelos visitantes, a cidade ainda consegue atrair milhares de pessoas que se identificam com o lugar. 


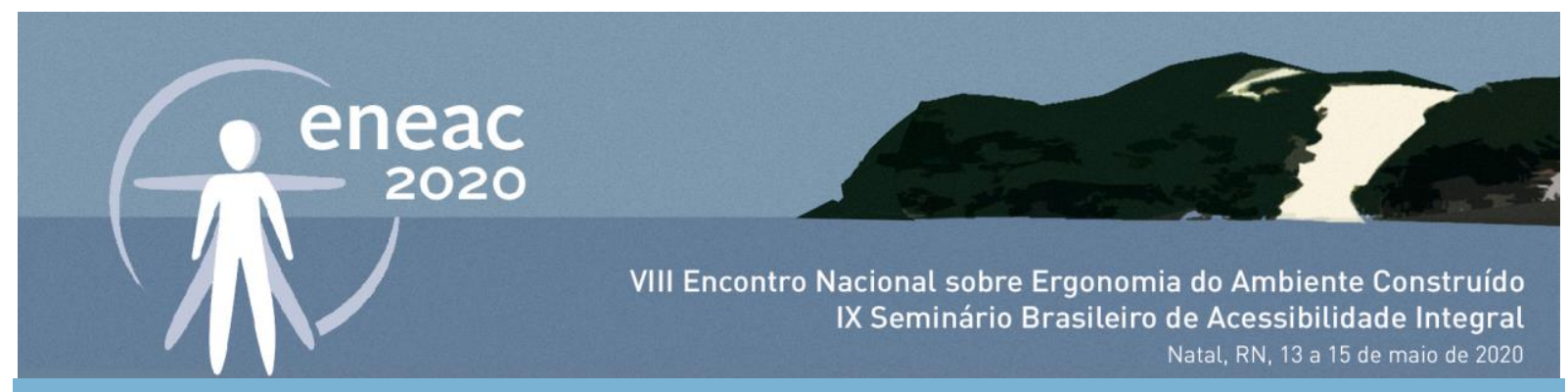

\section{COMPLEXO DA BASÍLICA DE SÃO FRANCISCO DAS CHAGAS DE CANINDÉ}

A cidade de Canindé, como centro de devoção a São Francisco, possui diversos pontos que podem ser visitados pelos romeiros: Basílica, Casa dos Milagres, estátua de São Francisco, Igreja de Nossa Senhora das Dores, Igreja do Cristo Rei, zoológico, anfiteatro etc. (Figura 1). Todos estes lugares são possíveis de se visitar caminhando, porém, a cidade tem uma topografia acidentada formando um vale. A estátua e a Igreja do Cristo Rei estão localizadas nos pontos altos da cidade urbanizada. Além disso, Canindé está localizada no sertão central do Ceará, ou seja, a incidência solar é muito forte e a temperatura sempre está bem elevada.

Por esta situação morfológica e climática, as pessoas que vão a Canindé e que não tem como se locomover até estes pontos mais altos, acabam por delimitar a sua visita apenas ao complexo da Basílica que está na parte mais baixa da cidade, vizinho ao Rio Canindé.

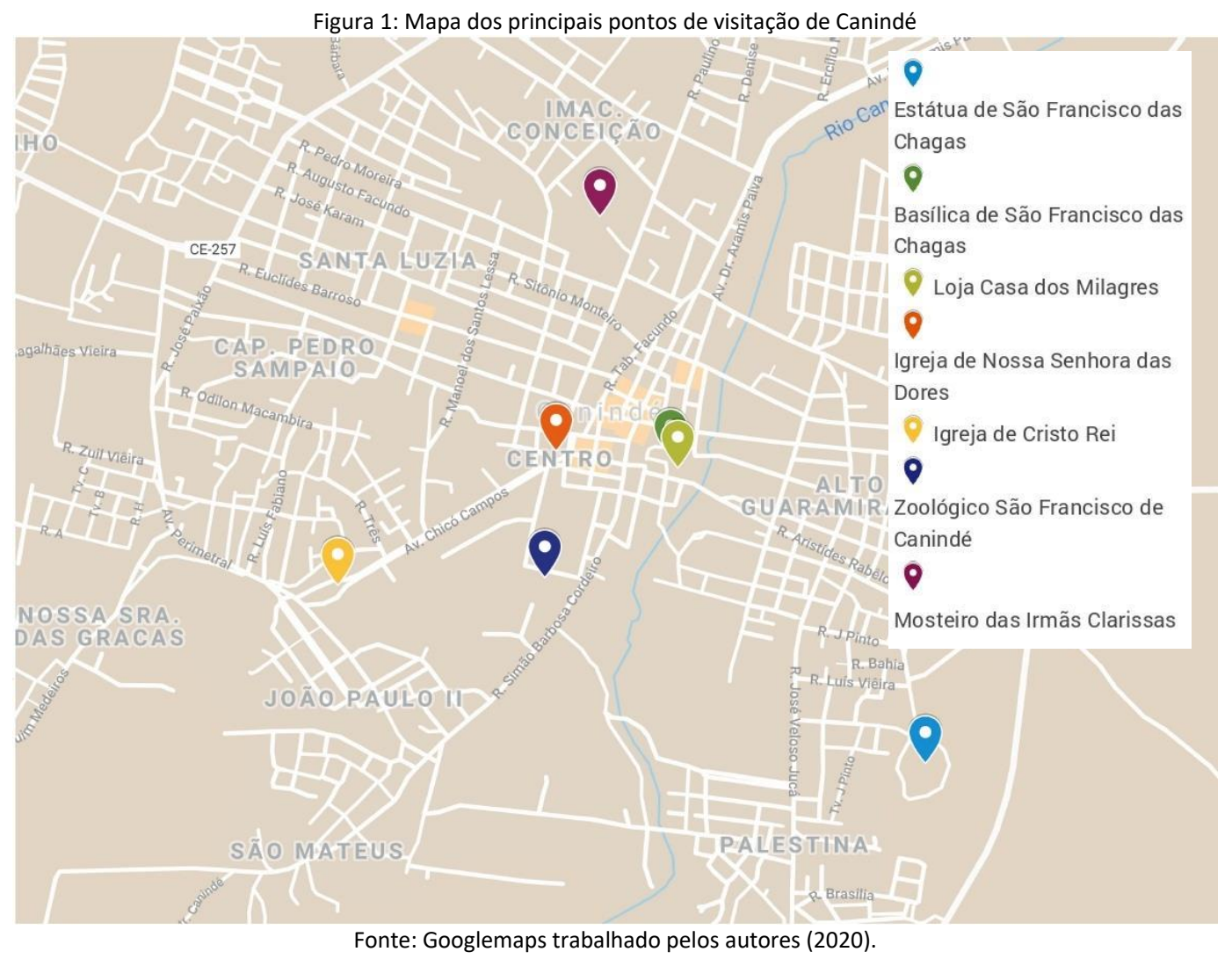

Assim, observando este grande fluxo de visitantes no complexo da Basílica, a ausência de acessibilidade é algo que se destaca a quem visita. Mesmo que muitas pessoas tomem partido dos obstáculos para cumprir promessas, como na escadaria; o lugar deve oferecer a opção de uma rota acessível para atender o grande número de pessoas com deficiências e de idosos que frequentam o espaço. 

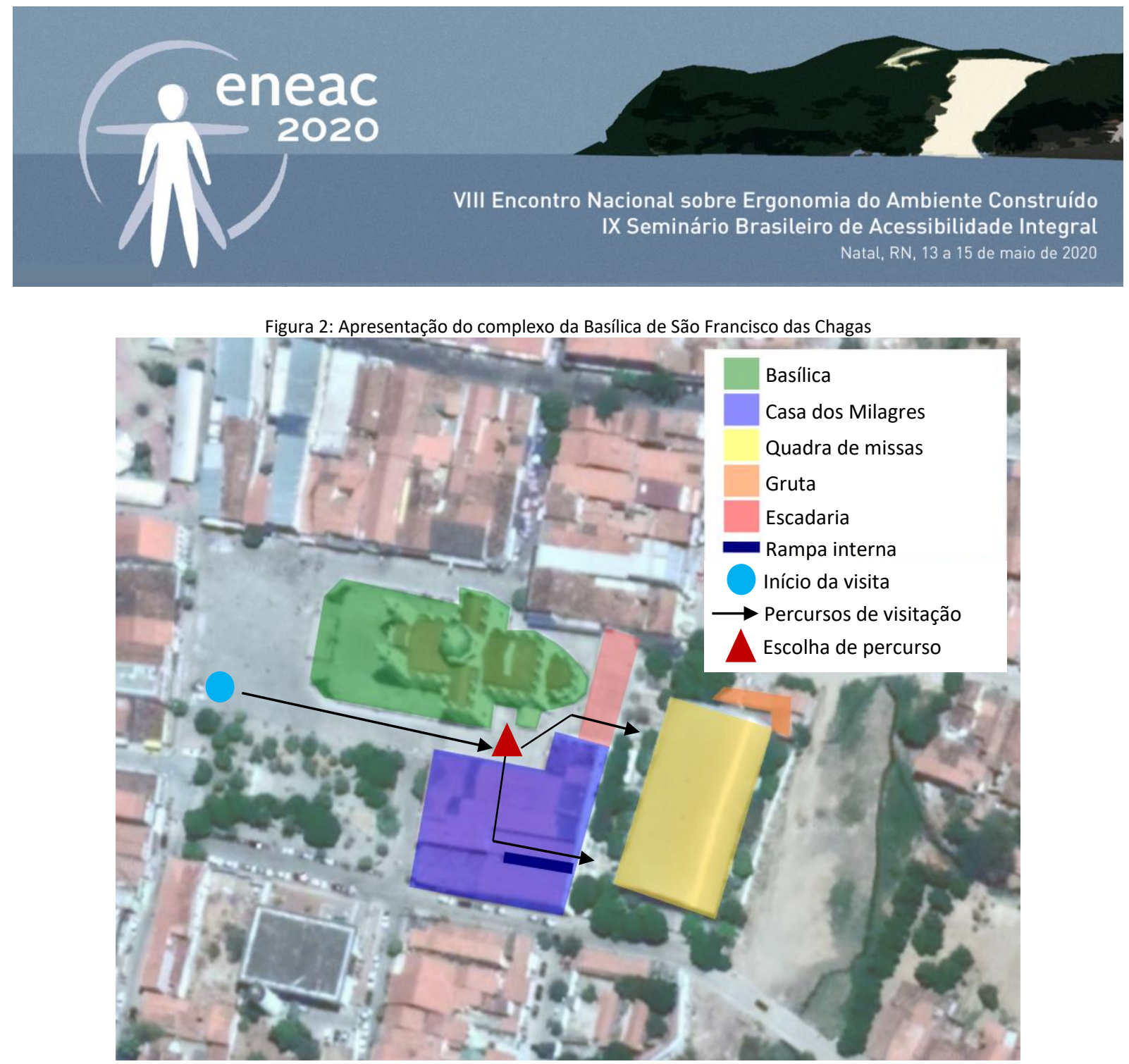

Fonte: Google Earth trabalhado pelos autores, 2020

O complexo da Basílica é formado pela própria igreja, pela quadra onde se celebram missas para públicos maiores, pela gruta onde as pessoas acendem velas e bebem água da fonte permanente e, por fim, pela Casa dos Milagres (Figura 2). Esta última edificação é onde os fiéis podem se confessar, entregar os seus ex-votos, comprar lembranças e orar na capela de São Damião.

As pessoas costumam chegar pela parte frontal da Basílica com a finalidade de visitar o local mais importante do complexo. A igreja está construída em metade de uma grande praça com piso em blocos de granito e está elevada 0,90m, aproximadamente, dando mais destaque. Para se ter acesso à igreja, as pessoas têm que subir este desnível de quase um metro. Na parte frontal, existem duas rampas idênticas sem nenhum corrimão de dupla altura (Figura 3). Já os acessos laterais são formados por escadas, também, sem corrimãos (Figura 4). Além de vencer esse desnível, ao entrar na própria Basílica, o visitante encontra um desnível de $0,07 \mathrm{~m}$ que, na entrada principal é vencido por um passeio inclinado e nas portas laterais, por um batente.

Uma outra entrada da igreja é encontrada próxima ao altar. Essa se diferencia das demais por apresentar uma rampa com inclinação acima do permitido de 8,33\% e sem corrimãos de dupla altura. Devido a localização, esta entrada é umas das mais utilizadas pelos fiéis que, aproveitam o acesso mais rápido para contemplação do altar principal (Figura5).

Ressalta-se que, até então, nenhumas das rampas e escadas encontradas possuem algum tipo de sinalização para deficientes visuais. 

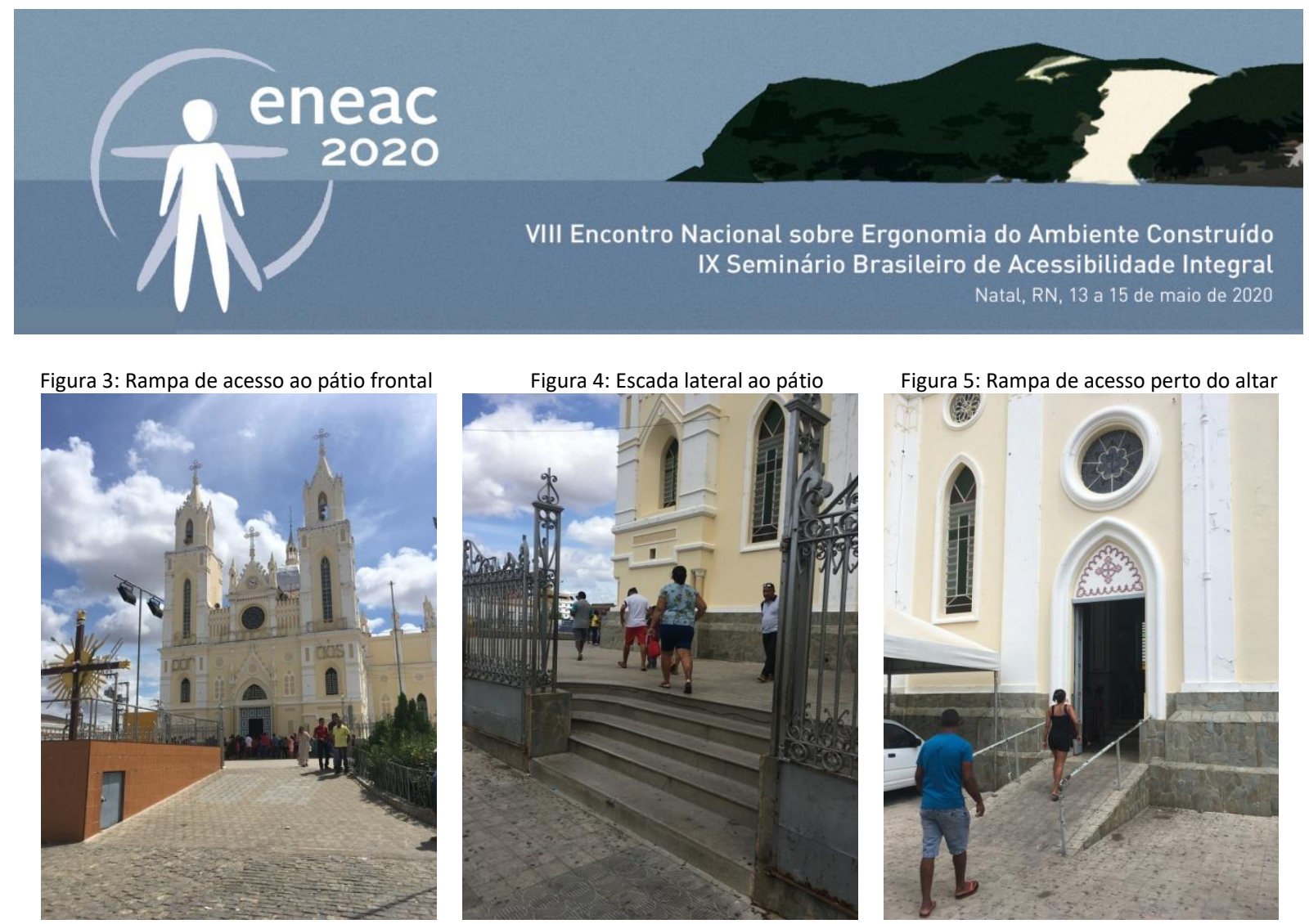

Fonte: acervo dos autores, 2019

Entre a Basílica e a Casa dos Milagres, onde acontece o grande fluxo de visitantes, encontramos pessoas caminhando entre as duas edificações e entre a praça maior e a escadaria. Mesmo com os fluxos cruzados, o espaço tem dimensões suficientes para fluir o grande público, principalmente após as missas na quadra.

Já a Casa dos Milagres, que também está elevada em relação ao nível do passeio exterior, possui rampas sem corrimãos para vencer os desníveis (Figuras 6 e 7). Ressalta-se que, a Casa dos Milagres, além de abrigar as salas de confissões, a sala dos ex-votos, a capela de São Damião, a emergência e a loja, é onde encontra-se a única rampa que dá acesso à quadra. Esta rampa é dividida em três trechos e está confinada na edificação que pode ficar fechada em determinados horários. Em relação a parte construtiva, rampa é bastante íngreme, não possui corrimãos, o piso é levemente antiderrapante e não há nenhuma sinalização para deficientes visuais (Figuras 8, 9 e 10).

Figura 6: Rampas de acesso à Casa dos Milagres
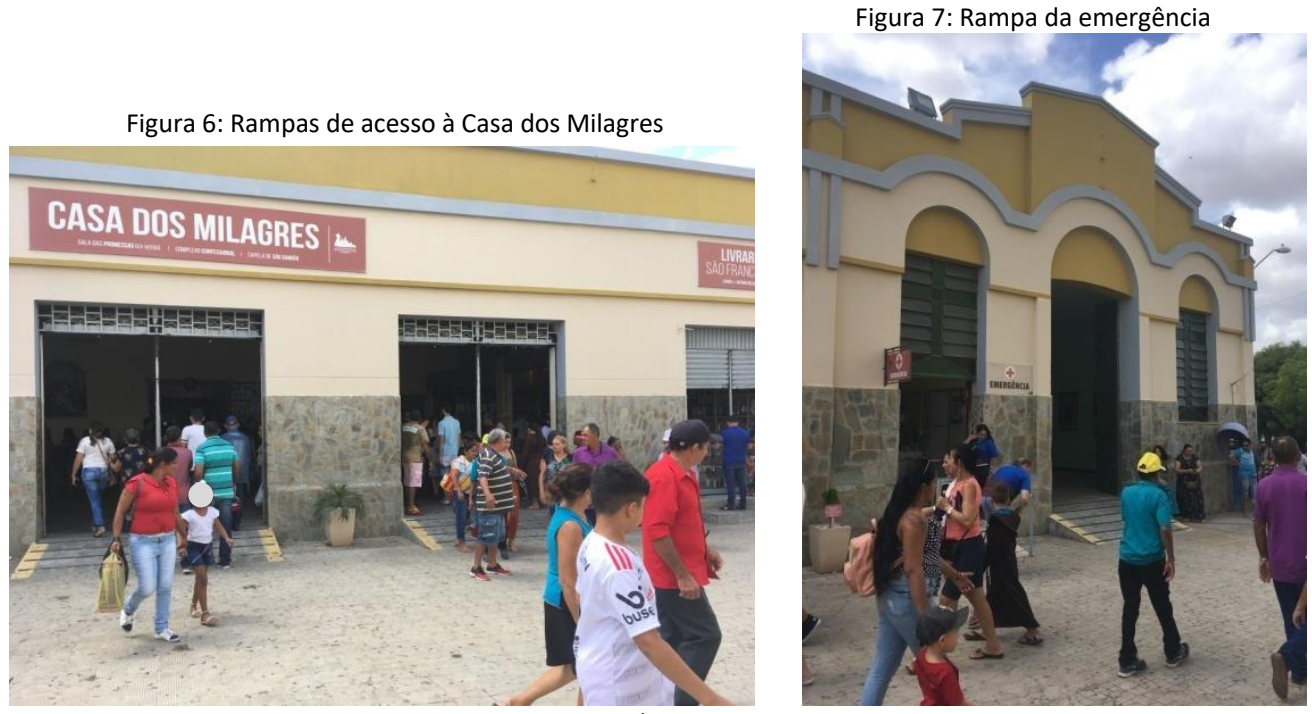

Fonte: acervo dos autores, 2019. 

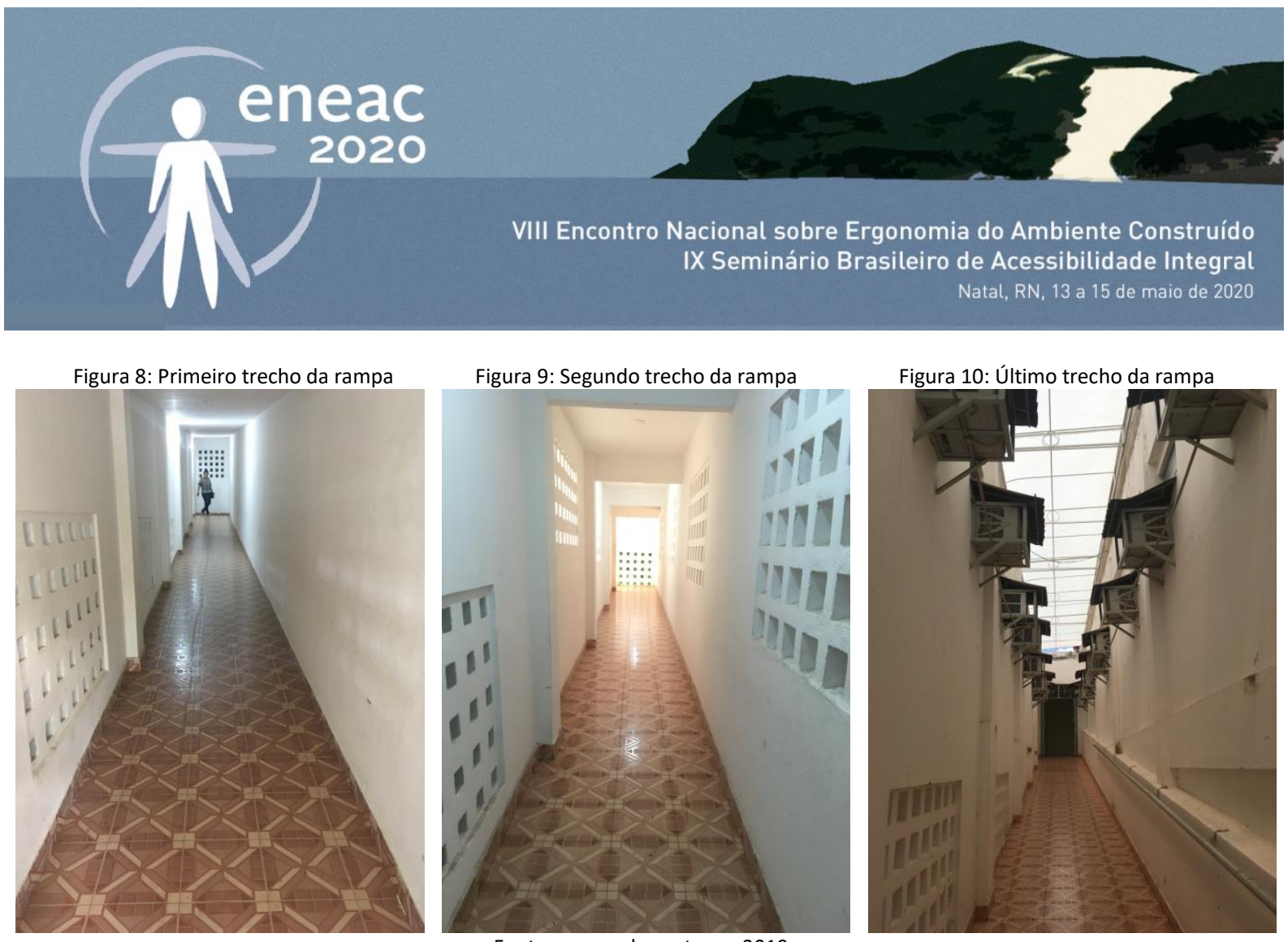

Fonte: acervo dos autores, 2019

No último trecho da rampa, no sentido de quem vai subindo, pode-se encontrar um corrimão de altura simples, mas que não acompanha toda a subida; além disso, aparelhos de ar condicionado soltam o ar quente das máquinas nesta parte confinada e fazem barulhos, trazendo desconforto térmico e acústico.

Quando o visitante desce esta rampa, com a finalidade de chegar na quadra das celebrações de missas, ele encontra mais outra rampa fora de norma. Essa possui uma inclinação superior à permitida (8,33\%), apresenta piso e resquícios de fitas antiderrapantes, além de corrimãos de altura simples. Ressalta-se que a rampa inicia em um passeio de piso em pedra portuguesa irregular (Figura 11). Após passar por esta pavimentação irregular, um passeio em cimentado segue até encontrar o piso da quadra. É por este pequeno trecho que as pessoas em cadeira de rodas ou com mobilidade reduzida preferem caminhar até porque a pavimentação adjacente é em calçamento.
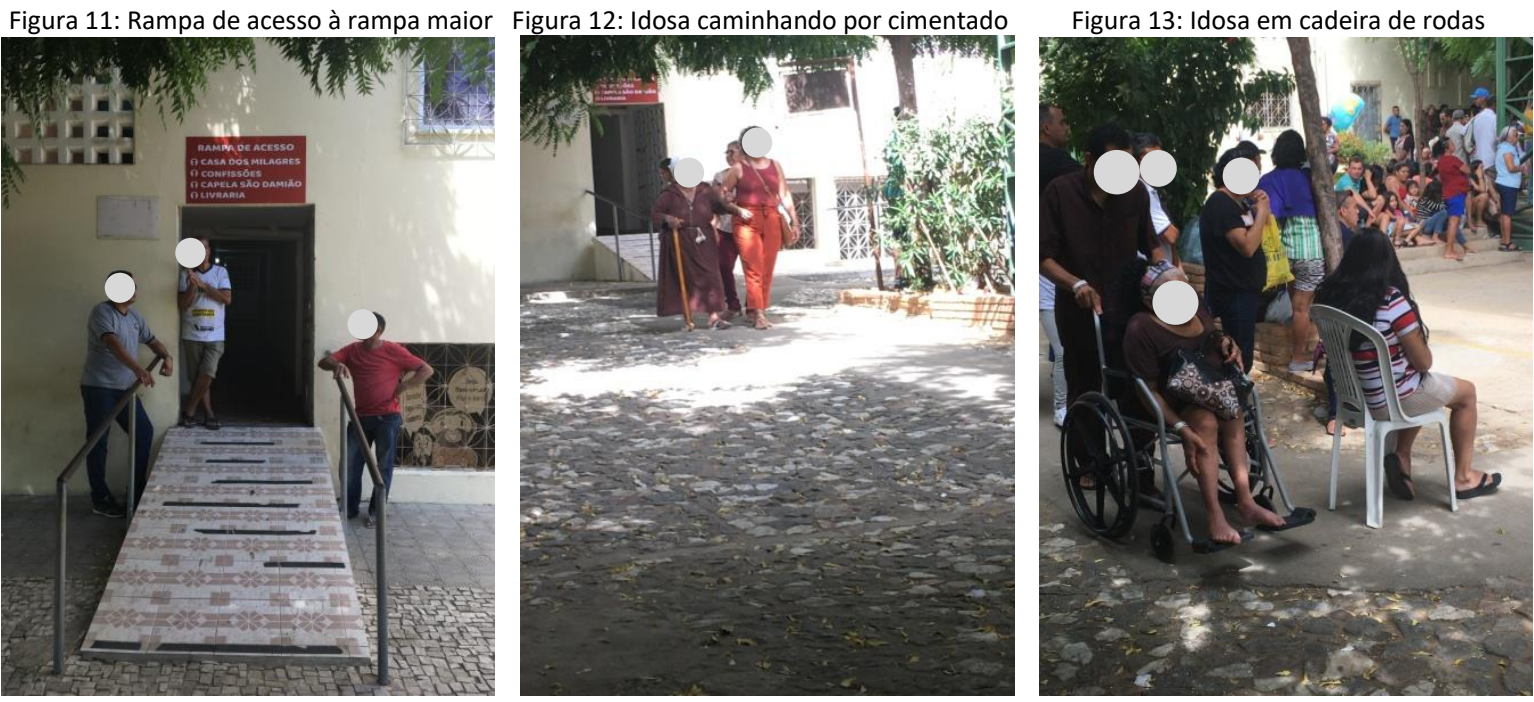

Fonte: acervo dos autores, 2019 


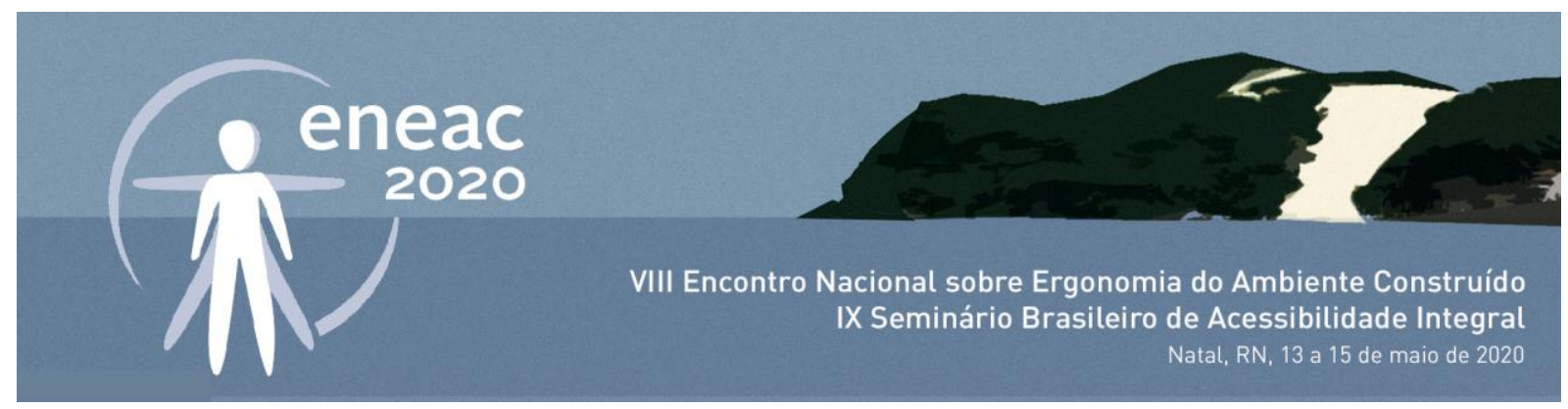

Observa-se que, apesar do cimentado ser em um pequeno trecho, muitas pessoas passam por ele e o utilizam como lugar plano, regular e confortável para permanecer de pé ou para colocar cadeiras. De acordo com Lei ${ }^{\circ}{ }^{13.146}$, de 6 de julho de 2015 que institui a Lei Brasileira de Inclusão da Pessoa com Deficiência, esta atitude ou comportamento configura-se como uma barreira atitudinal, impedindo ou prejudicando às condições de igualdade de uma pessoa com deficiência. Esta condição de igualdade pode ser considerada, também, o direito de ir e vir livremente sem impedimentos.

Mas o acesso a quadra de celebrações não é feito apenas pela rampa confinada na Casa dos Milagres, a outra opção é a escadaria que fica por de trás da Basílica. Por não saber da existência ou por não poder acessar a rampa facilmente, a grande maioria do público utiliza a escadaria para vencer o desnível de, aproximadamente, 3,5 metros. Além disso, a escadaria possui uma extensão de $26,5 \mathrm{~m}$ e está à céu aberto, diferenciando-se da rampa nos aspectos dimensionais e de conforto térmico. Porém, com 22 degraus, a escadaria inviabiliza a subida ou descida de pessoas em cadeira de rodas ou com alguma redução de locomoção. Para o público o idoso, os corrimãos existentes são de grande auxílio para o equilíbrio e para a força, principalmente durante a subida. Porém, os seis corrimãos presentes são com apenas uma altura e os que estão instalados nas alvenarias laterais são interrompidos antes da escada terminar.

Outro detalhe importante sobre a escadaria é que ela é toda em cimentado desempenado não apresentando contraste de cor e nem sinalização que diferencie o piso do espelho, além de não ter piso de alerta nos extremos da escadaria.
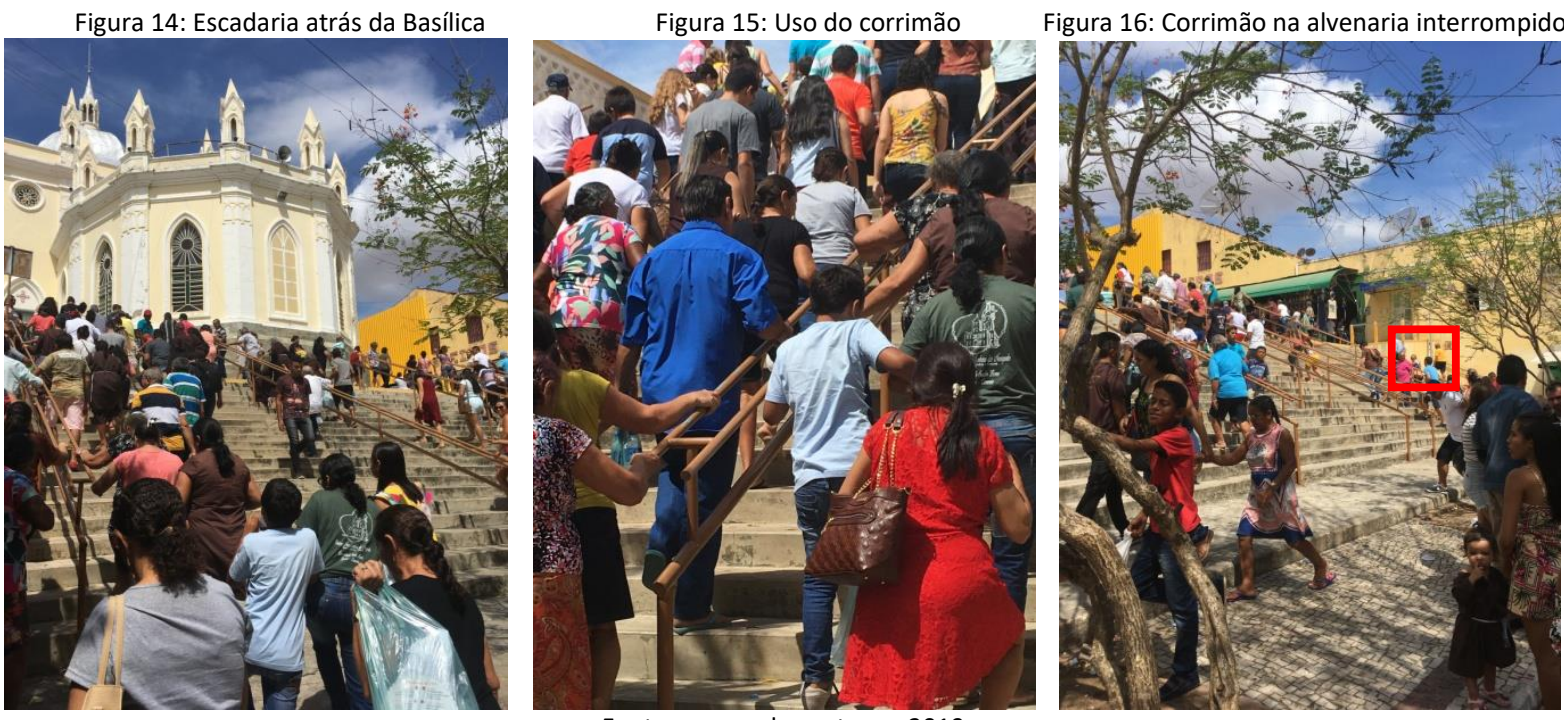

Fonte: acervo dos autores, 2019.

Por fim, a inacessibilidade se estende aos acessos da quadra das celebrações de missas que apresentam problemas de barreiras construtivas e atitudinais. Na questão construtiva, quando o visitante desce a escadaria, ele encontra um patamar em ladrilho que se prolonga por toda lateral da Casa do Milagres. Depois dos ladrilhos vem um passeio em pedra portuguesa e, logo depois, uma via de pedestre em calçamento. Logo após essa, o fiel volta a encontrar um passeio em pedra portuguesa para só então dar início ao cimentado polido da quadra de celebrações. 


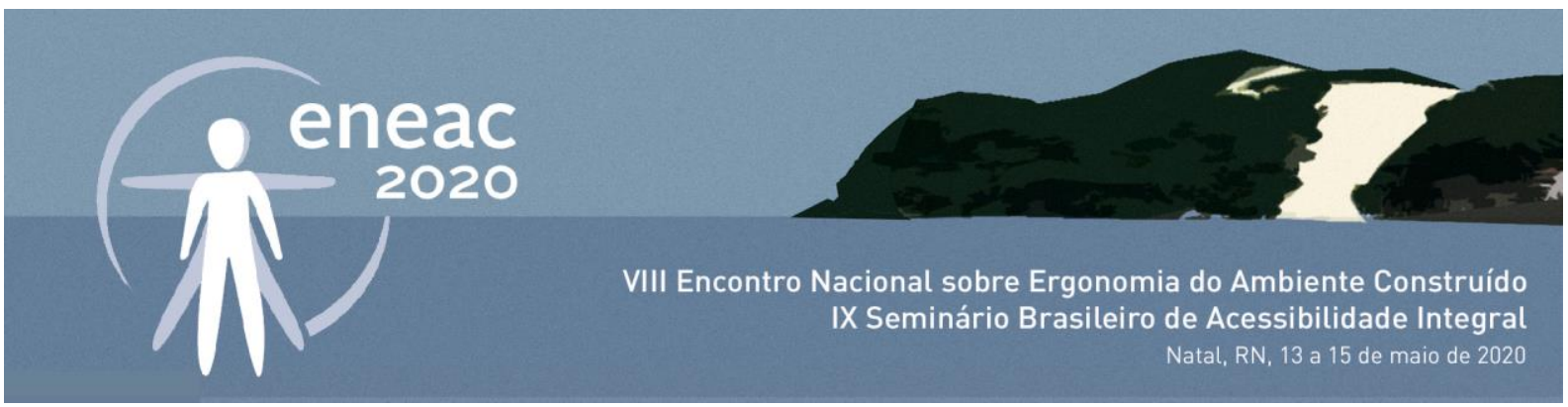

A cada mudança de pavimentação, há um desnível de aproximadamente $0,10 \mathrm{~m}$ de altura; porém, quem estiver em cadeira de rodas só terá duas opções de acessar a quadra. A primeira será pelo cimentado já apresentado próximo a saída da rampa confinada da Casa dos Milagres e a segunda opção por uma passagem no meio da quadra. Nesta passagem, foram feitas rampas improvisadas e cimentado sobre o pavimento de calçamento que já está parcialmente deteriorado.
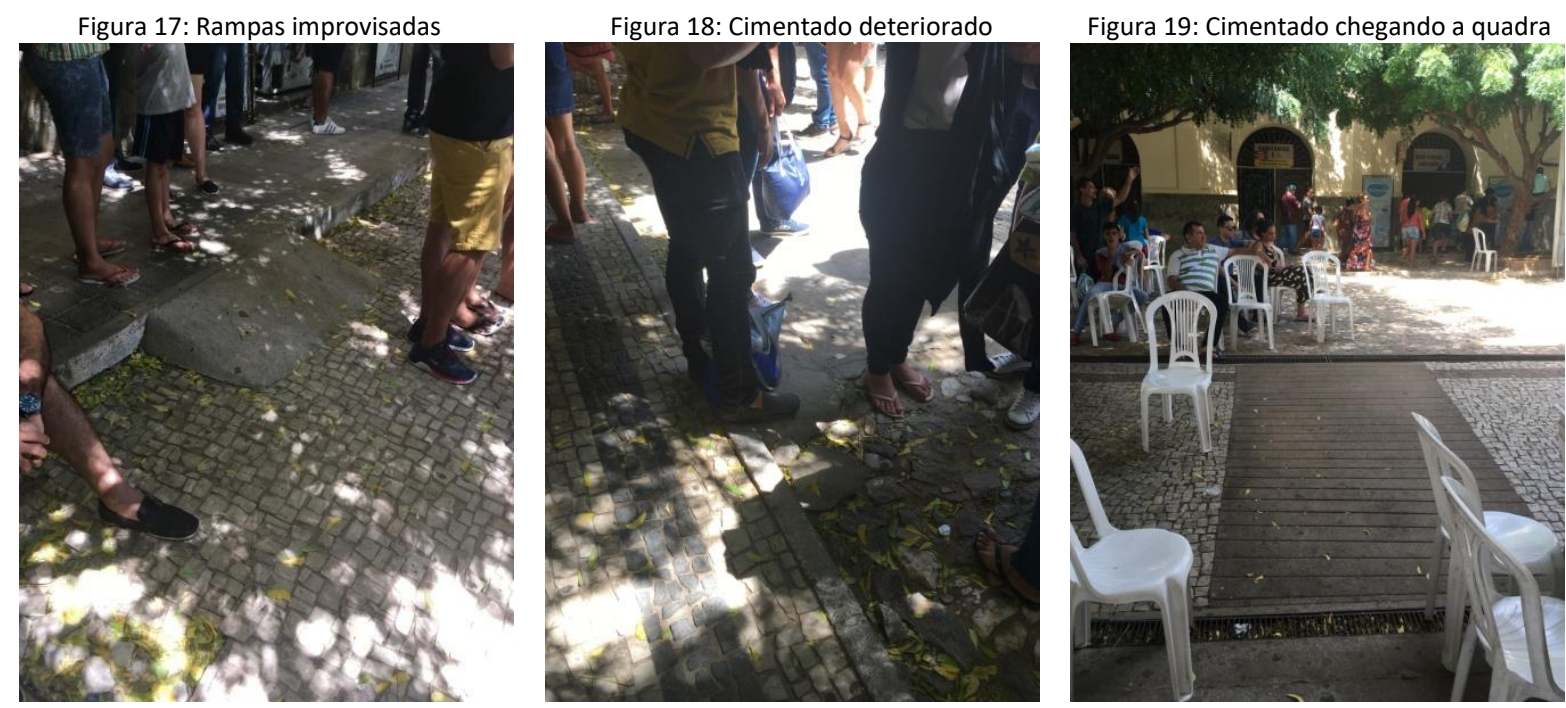

Fonte: acervo dos autores, 2019

Além disso, pode-se observar que as pessoas ainda colocam cadeiras justamente na faixa de circulação das pessoas em cadeira de rodas, demonstrando uma barreira atitudinal. Mas, não são só as atitudes do público em geral que promovem algum tipo de barreira, a própria igreja costuma passa suas instalações de som e energia em lugares inapropriados de circulação; podendo comprometer a movimentação dos fiéis como também pode gerar um risco de choque elétrico. Além disso, o acesso aos banheiros acessíveis é fechado exatamente no caminho mais curto.

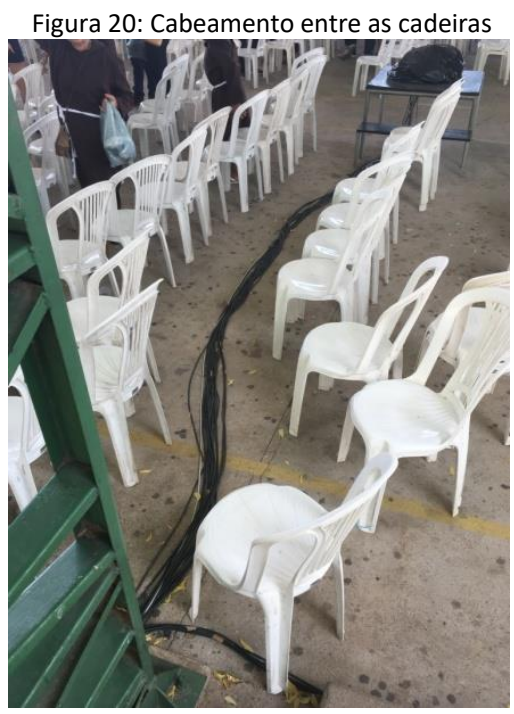

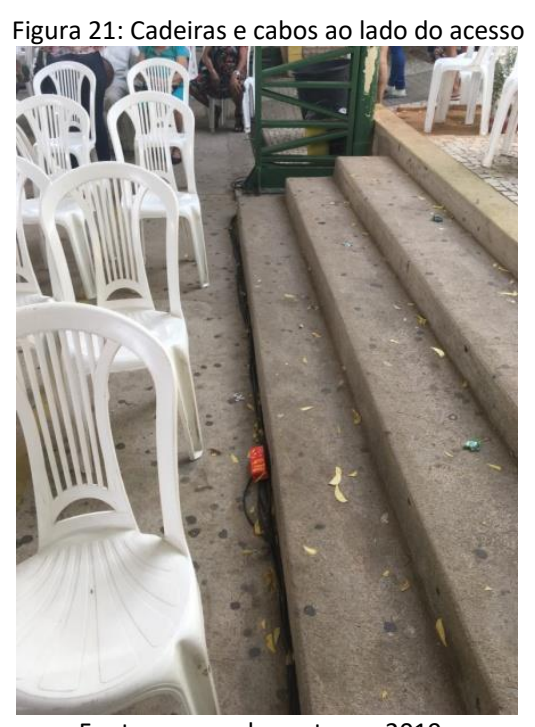

Fonte: acervo dos autores, 2019.

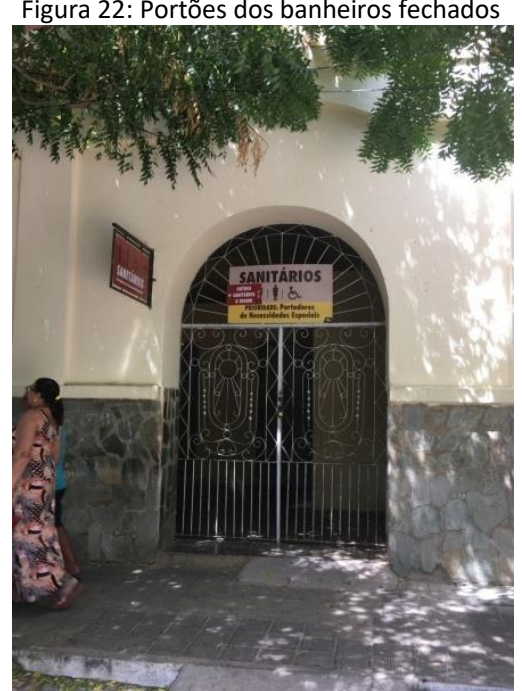




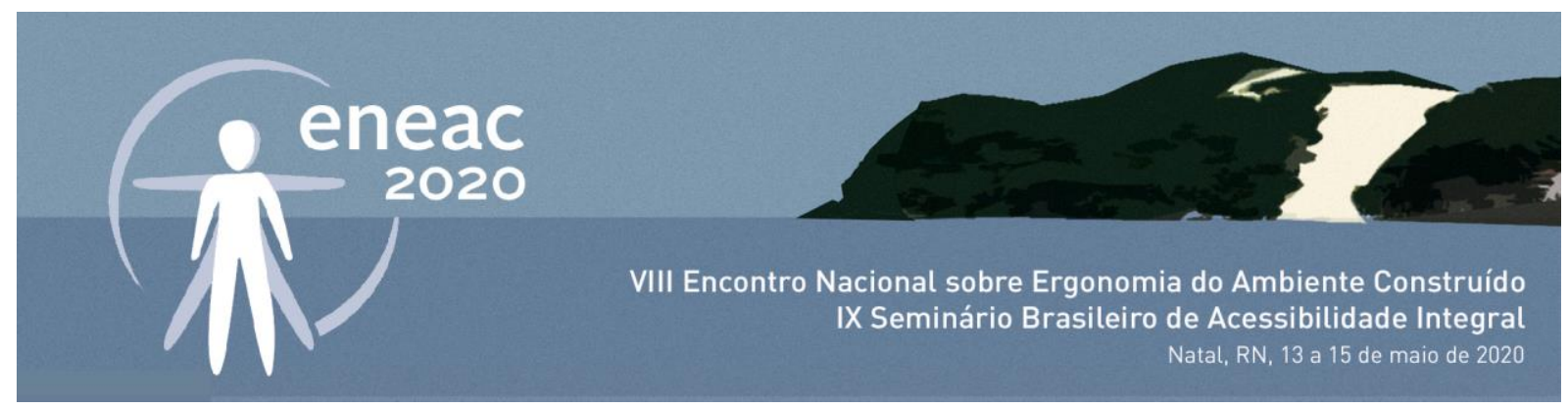

Assim, outros diversos pontos do complexo da Basílica apresentam algum tipo de barreira que podem interferir no usufruto do espaço livremente.

Ressalta-se que todos estes percursos, que são fora das edificações, além de serem utilizados por pessoas com objetivos religiosos, também é trajeto de circulação e espaço de lazer.

\section{CONSIDERAÇÕES FINAIS}

Observado que a cidade de Canindé é um grande centro religioso no estado do Ceará, muitas pessoas se deslocam até lá para peregrinar ou para apenas visitar. O público nativo e visitante é diverso, mas com um grande número de idosos e pessoas com alguma deficiência que tem o intuito de agradecer ao santo de devoção pelas graças alcançadas ou para pedir alguma benção. Assim, anualmente, muitos devotos de São Francisco das Chagas se lançam na fé e se esforçam no ato de agradecer as dádivas alcançadas.

Mesmo com este público constante, o que se percebe é que a cidade ainda deixa muito a desejar para os seus moradores e para os seus visitantes. Além, da topografia acidentada, os pontos principais de visitação não oferecem uma acessibilidade completa. Esta falta de ligação entre os lugares de forma fluida, só tende a dificultar o percurso de peregrinação dos romeiros e a segregar às pessoas durante a visitação.

O uso inadequado de revestimentos, a falta de rampas e sinalização básica para as pessoas com deficiência visual são os problemas que mais se destacam no complexo da Basílica que possui a mesma configuração há anos. Isso demonstra a necessidade urgente de intervenções pensadas e conectadas umas às outras. O espaço como um todo precisa ser inclusivo utilizando de técnicas de desenho universal, pois, intervenções pontuais não alcançam a real eficiência se estiverem desconectadas no contexto geral.

Por fim, ressalta-se a necessidade de sempre ver a acessibilidade como parte integrante do projeto e não como uma solução paliativa. Rampas sem as devidas inclinações e sinalizações acabam por se tornar obstáculos, por exemplo, que podem vir a dificultar a caminhabilidade ao invés de facilitar. Assim, Canindé necessita passar por uma remodelação do seu desenho de maneira que os seus moradores e seus visitantes consigam percorrer a cidade de forma agradável e sem barreiras.

\section{REFERÊNCIAS}

ASSOCIAÇÃO BRASILEIRA DE NORMAS TÉCNICAS. NBR 9050:2015. Acessibilidade a edificações, mobiliário, espaços e equipamentos urbanos. Rio de Janeiro: ABNT, 2015.

NBR 16537:2016. Acessibilidade - Sinalização tátil no piso - Diretrizes para elaboração de projetos e instalação. Rio de Janeiro: ABNT, 2016.

BRASIL. Lei n¹3.146, de 6 de julho de 2015. Institui a Lei Brasileira de Inclusão da Pessoa com Deficiência (Estatuto da Pessoa com Deficiência). Brasília, 2015.

Decreto $n^{\circ} 5.296$, de 2 de dezembro de 2004. Regulamenta as Leis nos 10.048, de 8 de novembro de 2000, que dá prioridade de atendimento às pessoas que especifica, e 10.098, de 19 de dezembro de 2000, que estabelece normas gerais e critérios básicos para a promoção da acessibilidade das pessoas portadoras de deficiência ou com mobilidade reduzida, e dá outras providências. Brasília, 2004. 


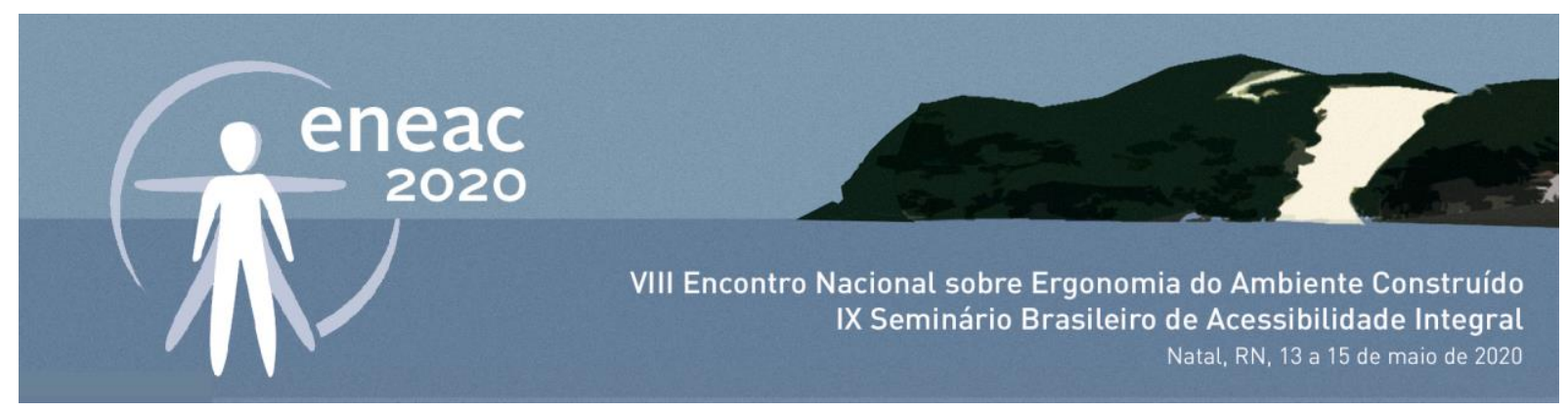

INSTITUTO BRASILEIRO DE GEOGRAFIA E ESTATíSTICA. Censo Demográfico 2010. Rio de Janeiro: IBGE, 2012.

DUARTE, Cristiane Rose; COHEN, Regina. Acessibilidade como fator de construção do lugar. In: Ornstein et al. (Orgs.). Desenho Universal: caminhos da acessibilidade no Brasil (pp. 81 - 94). São Paulo: Ed. Annablume, 2010.

GEHL, Jan. Cidades para pessoas. Tradução Anita Di marco. 2 ed. São Paulo: Perspectiva, 2013.

PREISER, Wolfgang F.E.; RABINOWITZ, Harvey Z.; WHITE, Edward T. Post-occupancy evaluation. New York: Van Nostrand Reinhold, 1988.

SANTOS, Fernando Henrique A. CAR - Centro de Apoio ao Romeiro em Canindé-CE. Trabalho Final de Graduação em Arquitetura e Urbanismo. Universidade Federal do Ceará. Fortaleza, 2018.

https://www.terra.com.br/noticias/dino/segundo-dados-deficientes-fisicos-representam-67-da-populacao-dobrasil,92b29cce3901f5772fe3ef8142149247ihbvtly7.html Acessado em: janeiro de 2020.

https://educacao.estadao.com.br/blogs/educacao-e-etc/com-nova-margem-de-corte-ibge-constata-67-de-pessoas-comdeficiencia-no-brasil/ Acessado em: janeiro de 2020 